\title{
Effects of repetitive magnetic stimulation on the growth of primarily cultured hippocampus neurons in vitro and their expression of iron-containing enzymes
}

This article was published in the following Dove Press journal:

Neuropsychiatric Disease and Treatment

\author{
Yirong Wang' \\ Kewei Fang ${ }^{2}$ \\ Shijia $\mathrm{He}^{\prime}$ \\ Yang Fan' \\ Juming $\mathrm{Yu}^{\prime}$ \\ Xiaodong Zhang' \\ 'Department of Neurology, Affiliated \\ Hospital of North Sichuan Medical \\ College, Sichuan, People's Republic of \\ China; ${ }^{2}$ Department of Radiology, \\ Affiliated Hospital of North Sichuan \\ Medical College, Sichuan, People's \\ Republic of China
}

Background: The mechanism of action of repetitive transcranial magnetic stimulation (rTMS) involves the generation of neuronal and action potentials utilizing induced currents in timevarying magnetic fields. However, the long-lasting and effective biological impact of magnetic stimulation does not appear to be completely explained by the transient magnetic field pulses. In this context, we hypothesized magnetic stimulation may affect the expression of iron-containing enzymes in neurons, mediating the long-lasting biological effects associated with this stimulus. Methods: Primarily cultured hippocampus neurons from SD rats were used as the cell model in this study. These were randomly divided into control, sham, and magnetic stimulation groups to probe into the effect of the magnetic field directly. The latter group received $40 \%, 60 \%$, and $100 \%$ maximal stimulator output Tesla $(1.68,2.52$, and $4.2 \mathrm{~T})$ with lowfrequency rTMS $(1 \mathrm{~Hz})$. The expression of iron-containing enzymes (catalase and aconitase) and non-ferrous enzymes (protein kinase A) was measured with Western blotting and ELISA. Results: The survival rates of neurons in the $40 \% \mathrm{~T}$ and $60 \% \mathrm{~T}$ groups were significantly increased in comparison to the controls $(P<0.05)$, while those in the $100 \% \mathrm{~T}$ group showed cell damage, with slightly disturbed neurite connections and decreased survival rate. Furthermore, catalase and aconitase expression was higher in all of the stimulated groups in comparison to controls $(P<0.05)$. On the other hand, the expression of the iron-containing enzymes decreased in the $100 \% \mathrm{~T}$ group in comparison with the $40 \% \mathrm{~T}$ and $60 \% \mathrm{~T}$ groups $(P<0.05)$. Meanwhile, the expression of protein kinase A was not significantly increased in the groups which underwent magnetic stimulation.

Conclusion: rTMS may increase the expression of ferrous enzymes but does not have a strong effect on non-ferrous enzymes. Excessive intensity of magnetic stimulation may reduce neuronal survival rate and affect the expression of iron-containing enzymes. The mechanism underlying the lasting effect of rTMS may be related to the increase of ferriferous expression induced by magnetic stimulation, with a clear correlation with stimulation intensity.

Keywords: hippocampus, iron-containing enzymes, neuromechanisms, repetitive magnetic stimulation

\section{Introduction}

Repetitive transcranial magnetic stimulation (rTMS) is considered to be a painless, non-invasive procedure which modifies neuronal functionality by using time-varying magnetic fields to generate conductive currents in different brain regions according to
Correspondence: Xiaodong Zhang Department of Neurology, Affiliated Hospital of North Sichuan Medical College, 63 Culture Road, Nanchong Sichuan Province 637000, People's

Republic of China

Tel +86 I58 8179 I828

Email zhangxiaodI63@I63.com 
the Faraday principle. ${ }^{1}$ However, magnetic stimulators produce a short-pulse magnetic field, while the biological effects of rTMS are long-lasting. ${ }^{2}$ Indeed, the long-term impact of rTMS does not seem to be adequately explained by the classically accepted assumption that magnetic fields induce changes in local electric currents to depolarize neurons and produce action potentials, which are very quick and transient events. ${ }^{3}$ On the other hand, the human body is known to contain a large amount of iron chelates. Based on the principles underlying the interactions between magnetic fields and iron, ${ }^{4}$ we hypothesize the spatial configuration of iron-containing enzymes may change into response to timevarying magnetic fields in turn affecting their expression. Therefore, rTMS may affect the expression of ironcontaining enzymes by acting on iron ions in cells, thereby mediating the long-lasting biological effects of this procedure. However, very few studies have focused on the effects of rTMS on neuronal ferrous and non-ferrous enzymes, nor the effect of magnetic stimulation different intensities on these enzymes. Therefore, we examined changes in the expression of ferrous enzymes (catalase, aconitase) and non-ferrous enzymes (protein kinase A) in primary hippocampal neurons, in order to initially explore the mechanisms underlying the biological effects of rTMS.

\section{Materials and methods}

\section{Animals}

SD rats were obtained within $24 \mathrm{hrs}$ of birth from the animal experimental center of North Sichuan Medical College, China (license No. SCXK(CHUAN) 2013-18). These animals are kept in a specific sterile facility, given a 12-hr light/dark cycle and free access to food and water. The study was approved by the animal experiment ethics committee of the North Sichuan Medical College, China. All experimental procedures were performed in accordance with the guidelines for animal research regulation of the Institute of Experimental Animal Resources.

\section{Materials}

The following materials were used for the procedures described in this article: DMEM high Glucose Medium (Thermo company, USA); FBS (Gibco, USA); B27 Additive (Invitrogen, USA); Neurobasal-A culture medium (Thermo Basal, USA); the MTT (Invitrogen, Waltham, USA); DMSO (Sigma, USA); Polylysine (Sigma, USA); $0.25 \%$ trypsin (Gibco, USA); PBS buffer (Thermo, USA); Rabbit anti-mouse NeuN monoclonal antibodies, Goat rabbit antigens (Wuhan Bioengineering Co., Ltd.); Goat anti-catalase antibodies (American R\&D Company); Goat anti-protein kinase $\mathrm{A}$ antibodies (American R\&D company); Rabbit anti-goat IgG (Jiangsukaiji Biotechnology Co., Ltd.); Cisphenolate ELISA kit (Shanghai Meixuan Biotechnology Co., Ltd.); Magnetic stimulator (model MagPro R3,Medtronic company, Denmark).

\section{Polylysine-coated Petri dishes and coverslips}

Pre-made polylysine $(0.1 \mathrm{mg} / \mathrm{mL})$ was added in 5 petri dishes to the bottom of the culture flask, which was placed in a cell incubator at $37^{\circ} \mathrm{C}$ and $5 \% \mathrm{CO} 2$ for $2 \mathrm{hr}$. Next, they were washed with PBS three times and set aside. A $1 \times 1 \mathrm{~cm}$ glass coverslip was placed in a six-well cell culture plate and pre-made polylysine $(0.1 \mathrm{mg} / \mathrm{mL})$ was then added to cover the bottom of the wells. This was then incubated at $37^{\circ} \mathrm{C}$ and $5 \% \mathrm{CO} 2$ for $2 \mathrm{hr}$, washed with PBS three times and set aside.

\section{Primary hippocampal neurons cultures in vitro ${ }^{5,6}$}

The brains of SD rats within $72 \mathrm{hrs}$ of birth were removed in order to isolate both hippocampi under sterile conditions with $2 \mathrm{~mL}$ of pre-chilled PBS solution. The tissue was minced to approximately $1 \mathrm{~mm}^{3}$ pieces with an ophthalmic scissor, incubated in $2 \mathrm{~mL} 0.25 \%$ trypsin solution mixed with $0.02 \%$ EDTA for $10 \mathrm{mins}$ at $37^{\circ} \mathrm{C}$, and then transferred to the centrifuge tube. Completely decentralized organization was achieved by repeated pipette blowing after termination of tissue digestion in $6 \mathrm{~mL}$ DMEM complete medium $(10 \%$ FBS in DMEM $+10 \mu \mathrm{L} / \mathrm{mL}$ penicillin $+100 \mu \mathrm{g} / \mathrm{mL}$ Streptomycin). The culture solution was filtered with a stainless steel mesh, and $2 \mathrm{~mL}$ of DMEM complete culture solution were added after discarding the supernatant by centrifugation at $1500 \mathrm{r} / \mathrm{min}$ during $5 \mathrm{mins}$, obtaining cell suspension by repeated beating. A cell density of $5-10 \times 10^{5} / \mathrm{mL}$ was obtained previously via inoculation onto poly-L-lysine-coated Petri dishes, which were then placed in a cell incubator at $37^{\circ} \mathrm{C}$ and $5 \% \mathrm{CO}_{2}$.

Approximately $24 \mathrm{hrs}$ after inoculation, the complete DMEM culture solution was removed and placed in a serum-free medium supplemented with Neurobasal + B27. Thereafter, the whole volume was changed every 2-3 days, and the cells were cultured until the seventh day of the experiment. 


\section{Neuron purity assessment}

Neuron purity was evaluated according to the operating process described by Ma J, Zhang Z et al. ${ }^{7}$ Neurons were cultured for 7 days, after being fixed with $4 \%$ paraformaldehyde for $30 \mathrm{mins}$ at room temperature. They were washed with PBS three times during 5 mins on each occasion, after aspiration of paraformaldehyde. The cells were incubated with $0.4 \%$ Triton at $37^{\circ} \mathrm{C}$ for 30 mins, and washed with PBS for 5 mins three times. Goat serum was blocked at $37^{\circ} \mathrm{C}$ for 30 mins, then rabbit anti-mouse NeuN monoclonal antibody was added to incubate overnight at $4^{\circ} \mathrm{C}$. The goat anti-rabbit secondary antibody was added after washing with PBS during 5 mins three times. After culturing for $1 \mathrm{hr}$ in darkness at room temperature, PBS washes were performed again three times during 5 mins. Next, fluorescence microscopy was performed.

\section{Experimental grouping and magnetic stimulation parameter settings}

Neurons were randomly divided into five groups: a control group, a sham group, and three groups which received magnetic stimulation at $40 \%(1 \mathrm{~Hz}, 1.68 \mathrm{~T}), 60 \%(1 \mathrm{~Hz}$, $2.52 \mathrm{~T})$, and $100 \%(1 \mathrm{~Hz}, 4.2 \mathrm{~T}) .{ }^{8}$ The control group was placed in the incubator without any treatment. For the stimulated groups, rTMS was delivered with a MCF-B65 butterfly coil $^{9}$ (Medtronic company, Denmark) with a $80 \mathrm{~mm}$ outer diameter connected to a MagPro R30 magnetic stimulation device of $4.2 \mathrm{~T}$ maximum output. The coil produced a focal field with the maximal intensity at the intersection of the round components. ${ }^{10}$ The stimulator handle was fixed on the top of each set of six-well plates with neuron culture platforms by a bracket and parallelled to the Petri dish at a distance of about $1 \mathrm{~cm},{ }^{9}$ without direct contact. ${ }^{11}$ Stimulation occurred at a fixed time every day for 5 consecutive days, with the stimulus parameters set at 1 $\mathrm{Hz}$ frequency, and intensity of $1.68,2.52$, and 4.2 $\mathrm{T}$ corresponding to the $40 \% \mathrm{~T}, 60 \% \mathrm{~T}$ and $100 \% \mathrm{~T}$ group, respectively. The stimulus pattern consisted of 3 pulse trains, each containing 100 pulses at $1 \mathrm{~Hz}$, and 60-s interval among sequences. Cells in the sham stimulation group were placed in the magnetic field environment with the same coil, yet the coil was disconnected from the power supply.

\section{Survival assessed with MTT colorimetry}

Neuronal survival rate was evaluated with the MTT assay. Primary cells were seeded in 96-well plates, and the abovementioned group was treated with magnetic stimulation.
After the fifth day of stimulation, $5 \mathrm{mg} / \mathrm{mL}$ of MTT solution 10 and $100 \mu \mathrm{L}$ of Neurobasal-A medium were added to each well, and the culture was continued in an incubator at $37^{\circ} \mathrm{C}$. The supernatant was centrifuged after $4 \mathrm{hrs}, 150 \mu \mathrm{L}$ of DMSO was added to each well, and the shaker was shaken at a low speed for 10 mins. ${ }^{12}$ The OD value of each well was measured at a 490 -nm wavelength using a Benchmark type microplate reader. Survival rate was calculated according to the formula: ${ }^{13}$ survival rate $(\%)=(\mathrm{OD}$ of each well/average OD of normal group) $\times 100 \%$.

\section{Western blotting}

Each group of neurons was removed from the medium and washed with PBS three times after 5 days of intervention with magnetic stimulation. Cell lysate was obtained utilizing a sonication cell disrupter for $30 \mathrm{~s}$, and then shaken on ice for 15 mins at $4^{\circ} \mathrm{C}$. The cell lysate was centrifuged at $12,000 \mathrm{r} / \mathrm{min}$ for $15 \mathrm{mins}$, and the supernatant was harvested for the collection of cell proteins. Then, protein concentration was quantitatively analyzed with the BCA method; $50 \mu \mathrm{g}$ of the total protein from each group were loaded and separated via SDS-PAGE gel electrophoresis, and then transferred onto PVDF membranes. These were washed with TBS three times during 10 mins. We proceeded to seal with milk at room temperature for $2 \mathrm{hrs}$, and the samples were then incubated with an anti-catalase antibody $(1: 2,000)$ and an anti-protein kinase A antibody $(1: 1,000)$ on a shaker overnight at $4^{\circ} \mathrm{C}$. After washing for 10 mins with TBST three times on the next day, blots were incubated for $1 \mathrm{hr}$ at room temperature with HRP-labeled rabbit anti-goat IgG (1:1,000). Proteins were visualized with the ECL method after washing three times with TBST. The relative expression of the target protein was analyzed by comparing OD with the internal reference $\beta$ actin band within the gel imaging system.

\section{ELISA}

A solid carrier with a 96-well strip plate precoated with the purified rat aconitine acid antibody. Then, setup 5 points of diluted standard such as $320,160,80,40$, and $20 \mathrm{ng} / \mathrm{L}$ obtained utilizing $150 \mu \mathrm{L}$ standard diluent at double dilution added $640 \mathrm{ng} / \mathrm{L}$ standard in the stock solution, and the last EP tube with50 $\mu \mathrm{L}$ standard diluent was the blank well with $0 \mathrm{ng} / \mathrm{L}$. The aconitase in the samples bound to the antibody attached to the solid carrier. Then, each well was covered with the plate sealer and incubated for $1 \mathrm{~h}$ at $37^{\circ} \mathrm{C}$. The wells were washed three times, and $50 \mu \mathrm{L}$ of HRP-labeled rat cisaconitase antibody was added to each well (except the blank 
well),

the antibody-antigen-enzyme-labeled-antibody complex. Protein visualization was conducted adding $90 \mu \mathrm{L}$ of substrate TMB solution to each well after incubation and washing. $50 \mu \mathrm{L}$ of sulfuric acid was then added as a stop solution. TMB substrate solution is converted to blue by HRP, and to yellow by acid of stop solution. Color intensity was positively correlated with aconitase contents in the samples. Finally, the absorbance of each well (OD value) was measured in a microplate reader at a 450-nm wavelength. A standard curve was plotted based on the OD value and the concentration of the diluted standard, where zero represented the blank well. From this curve, we calculated the concentration of aconitase in the protein samples.

\section{Statistical analysis}

Image Pro-Plus 5.0 software was used to calculate the gray value of the protein bands detected in primary hippocampal neurons. SPSS v13.0 was used for all statistical data analyses. Distribution normality and homogeneity of variance were evaluated in all data. All values were reported as mean \pm SD. One-way ANOVA was performed to compare means from multiple samples, if both normal distribution $(P>0.05)$ and homogeneity of variance $(P>0.05)$, followed by the SNK multiple range test for comparisons between groups. $P$-values $<0.05$ were considered statistically significant.

\section{Results}

\section{Morphological and purity of neuron cultures}

Immunofluorescence of primary hippocampal neurons cultured in vitro for 7 days showed plump cell bodies with regular morphology, clear nuclear and cytoplasmic

A

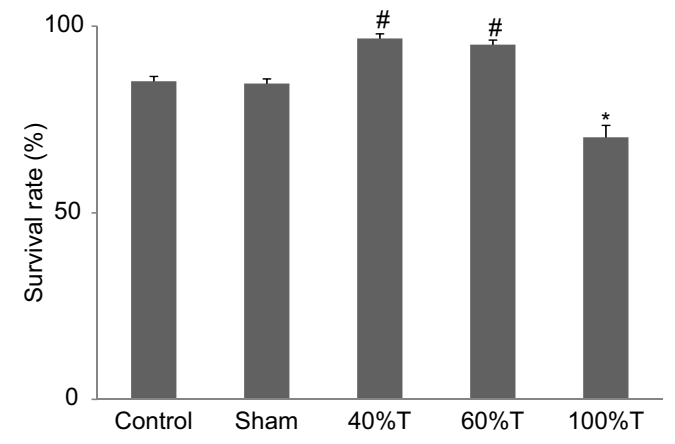

boundaries, and abundant interneuronal connections. Neurons were identified with anti-mouse NeuN monoclonal antibodies, and neuron purity was presented as the proportion of hippocampal neurons to total cells.

\section{Neuron survival test}

The cellular activity of hippocampal neurons treated with magnetic stimulation was measured by MTT to identify differences in cell survival among varying stimulation intensities. Cell viability showed no statistical difference in either the control and sham groups. Compared to the control group, neurons under $40 \% \mathrm{~T}$ and $60 \% \mathrm{~T}$ magnetic stimulation had increased neural survival rate $(P<0.05)$, while those under $100 \%$ intensity stimulation showed a significant decrease. The survival rate of neurons in the $40 \%$ and $60 \%$ intensity groups was higher than that in the $100 \%$ intensity stimulation group $(P<0.05)$ (Figure 1).

\section{Expression of catalase and protein kinase} $A$ in neurons

Western blotting and relative protein expression (Figure 2) showed similar levels of catalase and protein kinase A in the control and sham groups. Compared to the control group, the effects of different magnetic stimulation intensities on protein kinase A expression were not significant. On the other hand, $40 \% \mathrm{~T}$ and $60 \% \mathrm{~T}$ significantly increased catalase expression $(P<0.05)$. Although $100 \% \mathrm{~T}$ magnetic stimulation also increased catalase expression in comparison to controls, these levels were lower than those found in the $40 \%$ and $60 \%$ intensity group $(P<0.05)$.

\section{ELISA test}

The standard concentration was diluted from $320 \mathrm{ng} / \mathrm{L}$ to a concentration gradient. A curve was plotted,

\begin{tabular}{lc} 
Effect of magnetic stimulation on neuron survival rate \\
\hline Group & Survival rate(\%) \\
\hline Control & $85.01 \pm 3.28$ \\
Sham & $84.62 \pm 2.58$ \\
$40 \% \mathrm{~T}$ & $96.68 \pm 5.75$ \\
$60 \% \mathrm{~T}$ & $95.01 \pm 5.65$ \\
$100 \% \mathrm{~T}$ & $70.17 \pm 6.26$ \\
\hline
\end{tabular}

Figure I Survival rate of primary hippocampal neurons treated with different intensities of magnetic stimulation. (A) Histogram and (B) table presenting the results. Survival rate is presented as mean $\pm S D$; $* P<0.05$, compared to the control group; ${ }^{*} P<0.05$, compared to the $40 \%$ T and $60 \%$ T groups.

Abbreviation: $\mathrm{T}$, intensity. 


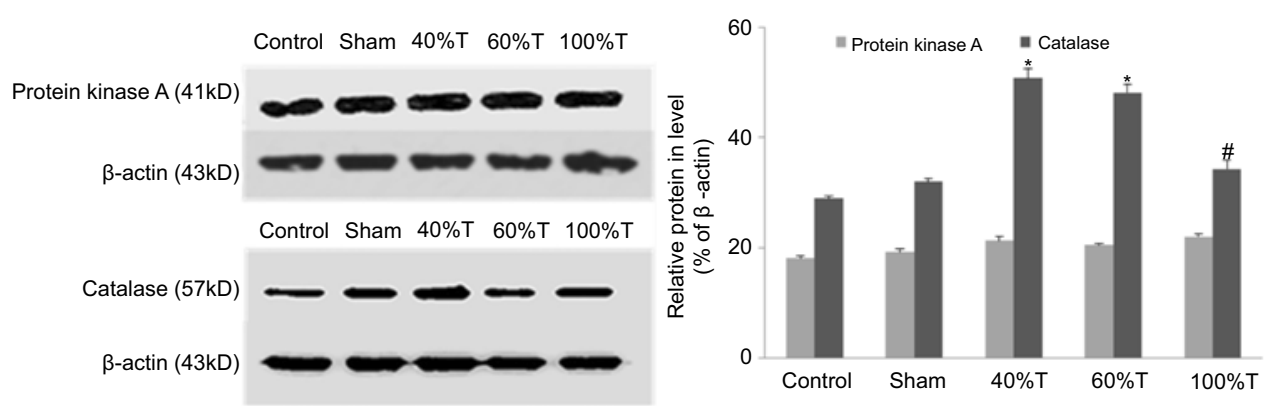

Figure 2 Expression of protein kinase $A$ and catalase in primary hippocampal neurons treated with different intensities of magnetic stimulation. $* P<0.05$ in comparison with the control group; ${ }^{\#} P<0.05$, compared to the $40 \% \mathrm{~T}$ and $60 \% \mathrm{~T}$. Repeat ANOVA was used.

Abbreviation: T, intensity.

where the OD of standard concentration was on the ordinate, and the dilution concentration on the abscissa, indicating a linear correlation between these variables (Figure 3A). Aconitase concentration in the control group $(390.5 \pm 14.849)$ was similar to that of the sham group (389.5 \pm 14.834$)$. Compared with the control group, aconitase concentrations were significantly increased in the groups treated with magnetic stimulation at $40 \% \mathrm{~T} 、 60 \% \mathrm{~T}$, and $100 \% \mathrm{~T} \quad(P<0.05)$; and the concentrations of aconitase in the $40 \% \mathrm{~T}$ and $60 \% \mathrm{~T}$ groups were higher than that of the $100 \% \mathrm{~T}$ groups $(P<0.05)$ (Figure $3 \mathrm{~B})$.

\section{Discussion}

\section{Effects of different intensity magnetic stimulation on neuron survival rate and iron-containing enzyme}

In recent years, rTMS has evolved into an effective method for basic neuroscience research,as well as useful clinical treatment. ${ }^{14,15}$ rTMS can be utilized in the treatment of depression, dementia, Parkinson's disease, migraine, and multiple sclerosis by altering neuronal excitability, neurotransmitter, and peptides metabolism, and immune function. ${ }^{16-18}$ Depending on the frequency and intensity of stimulation, rTMS can enhance or inhibit neuronal excitability. ${ }^{19,20} \mathrm{Ma}$ et al found ${ }^{21}$ hippocampal expression of synaptic protein markers to be increased in rTMS with low intensity at $1 \mathrm{~Hz}$, while high rTMS intensity further impaired synaptic plasticity and inhibited neuron growths, which is consistent with our results study. The influence of magnetic fields on the growth of neurons is thought to be related to both stimulation intensity and frequency, as well as the endurance of the particular neuron populations exposed to the magnetic field. ${ }^{21,22}$ Likewise, Western blotting and ELISA show similar effects on neuron survival rate. Indeed, rTMS with appropriate intensity had a positive effect on neuron survival rate and the expression of ferriferous such as catalase and aconitase, while excessive intensity aggravated neuronal damages, which is not conducive to the expression of ferriferous.
A

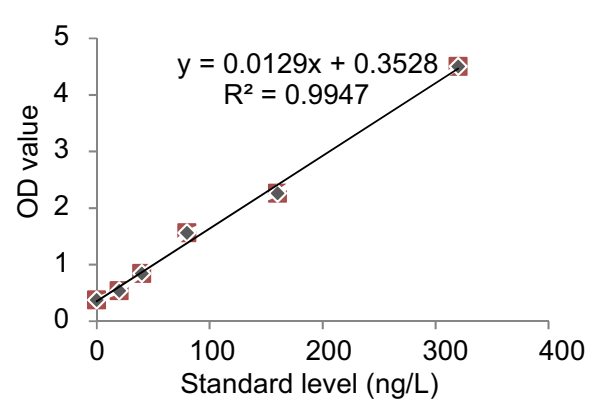

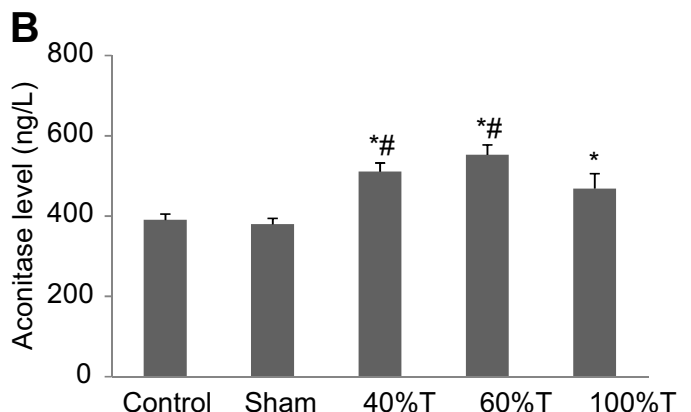

Figure 3 Aconitase concentrations as measured with ELISA in primary hippocampal neurons treated with different intensities of magnetic stimulation. (A) The linear regression equation between the OD value of the standard product and the concentration of aconitase; (B) histogram showing aconitase concentrations. $* P<0.05$, compared to the control group; ${ }^{\#} P<0.05$ compared to the $100 \%$ intensity group.

Abbreviation: $\mathrm{T}$, intensity. 
Expression analysis of iron-containing and non-ferrous enzymes on repeated magnetic stimulation

Human tissues hold iron-containing compounds, such as cytochromes, iron-sulfur proteins, and enzymes. ${ }^{23}$ In its chelate state, iron produces a magnetic field during the transfer of electrons between $\mathrm{Fe}^{2+}$ and $\mathrm{Fe}^{3.24,25}$ Biochemical studies suggest that magnetic stimulation may play an important role in improving cognition, controlling cell proliferation, and increasing cellular energy supply. ${ }^{26}$ This may be related to iron's and other isotopes' capacity or single-electron transfer and generating free radical pairs, facilitating magnetic catalysis. ${ }^{27}$

Studies on the mechanisms of action of magnetic stimulation on neuronal proteins and the ensuing biological effects remain scarce. We hypothesize some chelates in the human body — such as heme proteins - may be paramagnetic, at least weakly. In a time-varying magnetic field, the expression of enzymes containing these chelates may be changed due to modifications on their spatial configuration in response to a magnetic field. This may explain the long-lasting biological effects of magnetic stimulation beyond the immediate effects in the generation of action potentials. In order to confirm this hypothesis, we evaluated the expression of ferrous enzymes such as catalase and aconitase, along with non-ferrous protein kinase $\mathrm{A}$, in response to magnetic stimulation. These were selected as they are iron chelates that biochemically produce free radical pairs by single-electron transfer. ${ }^{28-30}$ Our results show catalase and aconitase expression significantly increased after magnetic stimulation, with no effect on protein kinase A. This preliminarily suggested that magnetic stimulation has a certain impact on iron-containing enzymes. This evidence tentatively confirms the role of iron-containing enzymes on sustaining the biological effects of magnetic stimulation in neurons.

Previous studies have confirmed that repeated magnetic stimulation has a protective effect against neuronal injury by oxidative stress $^{31,32}$ which may be an important therapeutic tool in the management of neurodegenerative diseases. Although magnetic stimulation is a non-invasive tool for the treatment of neurological disorders, ${ }^{33}$ the neurobiological and cellular mechanisms of rTMS are unclear, in particular regarding the reduction of oxidative stress. Ferrite is notoriously involved in cellular metabolism in the tricarboxylic acid cycle with mitochondria, being a sensitive target for oxidative stress. $^{34}$ In addition, Baek $\mathrm{A}$ et $\mathrm{al}^{35}$ reported that magnetic stimulation to be related to activation of signaling by calmodulin-dependent protein kinase II, which in turn intervenes in synaptic plasticity. Likewise, magnetic stimulation is closely related to synaptic plasticity changes of neurons. ${ }^{21}$ This study found that the concentration of neuronal iron-containing enzymes was significantly increased after repeated magnetic stimulation. We boldly hypothesize magnetic stimulation may produce long-lasting and effective biological effects on neurons by increasing the expression of iron-containing enzymes. Further exploration of the relationship between iron-containing and magnetic stimulation should provide a better understanding on the neurobiological mechanisms of neuroplasticity, along with possible clinical applications.

\section{Limitations}

This study has certain limitations. Although our results regarding aconitase and catalase are interesting, research in this area is scarce, and our findings should be compared with changes in other iron-containing proteins and copperor zinc-containing proteins, as well as erythrocytes functionality and plasma composition. Second, we used neurons in vitro, yet neuronal responses upon magnetic stimulation should also in vivo in animals. Third, in this study, neuronal survival rate upon magnetic stimulation was assessed with different intensities, yet always at a frequency of $1 \mathrm{~Hz}$. Thus, it remains unclear whether larger stimulation frequencies would offer similar results. Subsequent studies should further increase the frequency to levels such as 5 and10 Hz, in order to observe their influence on neuron survival rate and protein expression.

\section{Conclusion}

To the best of our knowledge, this is the first study to investigate the mechanisms underlying the biological effects of magnetic stimulation by assessing its relationship with iron-containing enzymes, as most other studies have assumed the effects of rTMS to be attributed to induced electric currents. Our results showed magnetic stimulation had a positive effect on iron-containing enzymes. In addition, we found that $100 \% \mathrm{~T}$ magnetic stimulation reduced neuronal survival and inhibited the expression of iron-containing enzymes, and this may be related to excessive stimulation intensity. Indeed, magnetic stimulation appears to have a positive effect on the expression of iron-containing enzymes, but the intensity and frequency of stimulation appears to be critical. 
In summary, iron-containing enzymes may be an especially important target of magnetic stimulation, serving as a bridge for repairing oxidative damage in neurons. In addition to generating induced currents, magnetic stimulation may also interfere with neurons by affecting ferrous enzymes, allowing transient magnetic field pulses to be converted into sustained biological effects. Further in vivo research is required to elucidate the effects of magnetic stimulation on other ferrous enzymes, as well as in other molecules, such as DNA, messenger RNA, and others, in order to clarify the mechanisms of action underlying the sustained biological impact of this procedure.

\section{Acknowledgment}

This study was supported by grants from the Health and Family Planning Council of Sichuan province (No. 140022).

\section{Author contributions}

$\mathrm{YW}, \mathrm{KF}$, and $\mathrm{XZ}$ conceived and designed the study. KF and JY provided the reagents, materials, and analysis tools. $\mathrm{SH}$ and $\mathrm{YF}$ analyzed the data. YW and $\mathrm{XZ}$ wrote the paper. Drafting of the manuscript was done by KF and SH. All authors contributed to data analysis, drafting and revising the article, gave final approval of the version to be published, and agree to be accountable for all aspects of the work.

\section{Disclosure}

The authors report no conflicts of interest in this work.

\section{References}

1. Kaskie RE, Ferrarelli F. Investigating the neurobiology of schizophrenia and other major psychiatric disorders with Transcranial Magnetic Stimulation. Schizophr Res. 2018;192:30-38. doi:10.1016/j. schres.2017.04.045

2. Di Lazzaro V. Biological effects of non-invasive brain stimulation. Handb Clin Neurol. 2013;116:367-374. doi:10.1016/B978-0-44453497-2.00030-9

3. Lee JY, Park HJ, Kim JH, Cho BP, Cho SR, Kim SH. Effects of lowand high-frequency repetitive magnetic stimulation on neuronal cell proliferation and growth factor expression: a preliminary report. Neurosci Lett. 2015;604:167-172. doi:10.1016/j.neulet.2015.07.038

4. Shokrollahi S, Ghanati F, Sajedi RH, Sharifi M. Possible role of iron containing proteins in physiological responses of soybean to static magnetic field. J Plant Physiol. 2018;226:163-171. doi:10.1016/j. jplph.2018.04.018

5. Clarke D, Penrose MA, Penstone T, et al. Frequency-specific effects of repetitive magnetic stimulation on primary astrocyte cultures. Restor Neurol Neurosci. 2017;35:557-569. doi:10.3233/RNN-160708

6. Baek A, Kim JH, Pyo S, et al. The differential effects of repetitive magnetic stimulation in an in vitro neuronal model of ischemia/ reperfusion injury. Front Neurol. 2018;9:50. doi:10.3389/ fneur.2018.00050
7. Ma J, Zhang Z, Su Y, et al. Magnetic stimulation modulates structural synaptic plasticity and regulates BDNF-TrkB signal pathway in cultured hippocampal neurons. Neurochem Int. 2013;62:84-91. doi:10.1016/j.neuint.2012.11.010

8. Grehl S, Martina D, Goyenvalle C, Deng ZD, Rodger J, Sherrard RM. In vitro magnetic stimulation: a simple stimulation device to deliver defined low intensity electromagnetic fields. Front Neural Circuits. 2016;10:85. doi:10.3389/fncir.2016.00085

9. Rueter D. Induction coil as a non-contacting ultrasound transmitter and detector: modeling of magnetic fields for improving the performance. Ultrasonics. 2016;65:200-210. doi:10.1016/j.ultras. 2015.10.003

10. Banerjee J, Sorrell ME, Celnik PA, Pelled G. Immediate effects of repetitive magnetic stimulation on single cortical pyramidal neurons. PLoS One. 2017;12:e0170528. doi:10.1371/journal.pone.0170528

11. Peterchev AV, Wagner TA, Miranda PC, et al. Fundamentals of transcranial electric and magnetic stimulation dose: definition, selection, and reporting practices. Brain Stimul. 2012;5:435-453. doi:10.1016/j.brs.2011.10.001

12. Yu Z, Men Y, Dong P. Schwann cells promote the capability of neural stem cells to differentiate into neurons and secret neurotrophic factors. Exp Ther Med. 2017;13:2029-2035. doi:10.3892/ etm. 2017.4183

13. Abbasnia K, Ghanbari A, Abedian M, Ghanbari A, Sharififar S, Azari H. The effects of repetitive transcranial magnetic stimulation on proliferation and differentiation of neural stem cells. Anat Cell Biol. 2015;48:104-113. doi:10.5115/acb.2015.48.2.104

14. Goldsworthy MR, Pitcher JB, Ridding MC. The application of spaced theta burst protocols induces long-lasting neuroplastic changes in the human motor cortex. Eur J Neurosci. 2012;35:125-134. doi:10.1111/ j.1460-9568.2011.07924.x

15. Shin SS, Krishnan V, Stokes W, et al. Transcranial magnetic stimulation and environmental enrichment enhances cortical excitability and functional outcomes after traumatic brain injury. Brain Stimul. 2018;11:1306-1313. doi:10.1016/j.brs.2018.07.050

16. Randver R. Repetitive transcranial magnetic stimulation of the dorsolateral prefrontal cortex to alleviate depression and cognitive impairment associated with Parkinson's disease: a review and clinical implications. $J$ Neurol Sci. 2018;393:88-99. doi:10.1016/j. jns.2018.08.014

17. Hulst HE, Goldschmidt T, Nitsche MA, et al. rTMS affects working memory performance, brain activation and functional connectivity in patients with multiple sclerosis. J Neurol Neurosurg Psychiatry. 2017;88:386-394. doi:10.1136/jnnp-2016-314224

18. Leahu P, Matei A, Groppa S. Transcranial magnetic stimulation in migraine prophylaxis. J Med Life. 2018;11:175-176.

19. Pleger B, Blankenburg F, Bestmann S, et al. Repetitive transcranial magnetic stimulation-induced changes in sensorimotor coupling parallel improvements of somatosensation in humans. J Neurosci. 2006;26:1945-1952. doi:10.1523/JNEUROSCI.4097-05.2006

20. Lu X, Bao X, Li J, et al. High-frequency repetitive transcranial magnetic stimulation for treating moderate traumatic brain injury in rats: a pilot study. Exp Ther Med. 2017;13:2247-2254. doi:10.3892/ etm. 2017.4283

21. Ma J, Zhang Z, Kang L, et al. Repetitive transcranial magnetic stimulation (rTMS) influences spatial cognition and modulates hippocampal structural synaptic plasticity in aging mice. Exp Gerontol. 2014;58:256-268. doi:10.1016/j.exger.2014.08.011

22. Shang Y, Wang X, Shang X, et al. Repetitive transcranial magnetic stimulation effectively facilitates spatial cognition and synaptic plasticity associated with increasing the levels of BDNF and synaptic proteins in Wistar rats. Neurobiol Learn Mem. 2016;134 (Pt B):369-378. doi:10.1016/j.nlm.2016.08.016

23. Zhang DL, Ghosh MC, Rouault TA. The physiological functions of iron regulatory proteins in iron homeostasis - an update. Front Pharmacol. 2014;5:124. doi:10.3389/fphar.2014.00124 
24. Edwards MJ, Hall A, Shi L, et al. The crystal structure of the extracellular 11-heme cytochrome Und A reveals a conserved 10-heme motif and defined binding site for soluble iron chelates. Structure. 2012;20:1275-1284. doi:10.1016/j.str.2012.04.016

25. Boehm-Sturm P, Haeckel A, Hauptmann R, Mueller S, Kuhl CK, Schellenberger EA. Low-molecular-weight iron chelates may be an alternative to gadolinium-based contrast agents for T1-weighted contrast-enhanced MR imaging. Radiology. 2018;286:537-546. doi:10.1148/radiol.2017170116

26. Goodwill AM, Lum J, Hendy AM, et al. Using non-invasive transcranial stimulation to improve motor and cognitive function in Parkinson's disease: a systematic review and meta-analysis. Sci Rep. 2017;7:14840. doi:10.1038/s41598-017-13260-z

27. Buchachenko A, Lawler RG. New possibilities for magnetic control of chemical and biochemical reactions. Acc Chem Res. 2017;50:877-884. doi:10.1021/acs.accounts.6b00608

28. Aida L, Soumaya G, Myriam E, Mohsen S, Hafedh A. Effects of static magnetic field exposure on plasma element levels in rat. Biol Trace Elem Res. 2014;160:67-72. doi:10.1007/s12011-014-9987-6

29. Holmes-Hampton GP, Ghosh MC, Rouault TA. Methods for studying iron regulatory protein 1: an important protein in human iron metabolism. Methods Enzymol. 2018;599:139-155. doi:10.1016/bs. mie.2017.09.006
30. Lu Z, Hunter T. Metabolic kinases moonlighting as protein kinases. Trends Biochem Sci. 2018;43:301-310. doi:10.1016/j.tibs.2018. 01.006

31. Tunez I, Montilla P, Del CMM, Medina FJ, Drucker-Colin R. Effect of transcranial magnetic stimulation on oxidative stress induced by 3-nitropropionic acid in cortical synaptosomes. Neurosci Res. 2006;56:91-95. doi:10.1016/j.neures.2006.05.012

32. Liu W, Du Y, Liu J, et al. Effects of atrazine on the oxidative damage of kidney in Wister rats. Int J Clin Exp Med. 2014;7:3235-3243.

33. Ni Z, Chen R. Transcranial magnetic stimulation to understand pathophysiology and as potential treatment for neurodegenerative diseases. Transl Neurodegener. 2015;4:22. doi:10.1186/s40035-0150045-x

34. Khodagholi F, Shaerzadeh F, Montazeri F. Mitochondrial aconitase in Neurodegenerative disorders: role of a metabolism-related molecule in neurodegeneration. Curr Drug Targets. 2018;19(8):973-985. doi:10.2174/1389450118666170816124203

35. Baek A, Park EJ, Kim SY, et al. High-Frequency Repetitive Magnetic Stimulation Enhances the Expression of Brain-Derived Neurotrophic Factor Through Activation of $\mathrm{Ca}(2+)$-Calmodulin-Dependent Protein Kinase II-cAMP-Response Element-Binding Protein Pathway. Front Neurol. 2018;9:285. doi:10.3389/fneur.2018.00285

\section{Publish your work in this journal}

Neuropsychiatric Disease and Treatment is an international, peerreviewed journal of clinical therapeutics and pharmacology focusing on concise rapid reporting of clinical or pre-clinical studies on a range of neuropsychiatric and neurological disorders. This journal is indexed on PubMed Central, the 'PsycINFO' database and CAS, and is the official journal of The International Neuropsychiatric Association (INA). The manuscript management system is completely online and includes a very quick and fair peer-review system, which is all easy to use. Visit http://www.dovepress.com/testimonials.php to read real quotes from published authors. 